\title{
Relationship between Pituitary-Thyroid Axis Hormones and Anthropometric Parameters in Czech Adult Population
}

\author{
M. DVOŘÁKOVÁ, M. HILL, J. ČEŘOVSKÁ, Z. POBIŠOVÁ, R. BÍLEK, \\ P. HOSKOVCOVÁ, V. ZAMRAZIL, V. HAINER \\ Institute of Endocrinology, Prague, Czech Republic
}

Received November 12, 2007

Accepted January 28, 2008

On-line February 13, 2008

\begin{abstract}
Summary
Although the relationships between thyroid function and anthropometric parameters were studied in patients with thyroid disorders and in morbidly obese subjects, such data in normal healthy population are scarce. In our study, relationships between factors of body composition, fat distribution and age with hormones of the pituitary-thyroid axis were evaluated in a large, randomly selected sample of normal adult Czech population comprising of 1012 men and 1625 women. Our results exhibited weak, but significant relationships between body composition, body fat distribution and the parameters of pituitary-thyroid axis. Some of these associations were genderspecific. As shown by backward stepwise regression model, body fat distribution evaluated by centrality index (subscapular/triceps skinfold ratio) was negatively associated with free triiodothyronine (fT3) serum levels only in women, while a positive correlation of fT3 with BMI was specific for men. BMI was inversely related to free thyroxine (fT4) concentrations in women but not in men. The centrality index (CI) was positively related to TSH levels in both genders. The fT3/fT4 ratio, reflecting deiodinase activity, was inversely related to age and positively related to BMI in both genders, while the highly significant negative correlation between $\mathrm{CI}$ and fT3/fT4 ratio was specific for women.
\end{abstract}

\section{Key words}

Anthropometry - Body composition - Body fat distribution • Thyrotropin $\bullet$ Free thyroxine $\bullet$ Free triiodothyronine

\section{Corresponding author}

M. Dvořáková, Institute of Endocrinology, Národní třída 8, 11694 Prague 1, Czech Republic. E-mail: mdvorakova@endo.cz

\section{Introduction}

Although the relationships between thyroid function and anthropometric parameters were studied in patients with thyroid disorders and in morbidly obese subjects before and after weight reduction (Kozlowska and Rosolowska-Huszcz 2004), data on these associations in random population samples is rather scarce. Until now only a few epidemiological studies evaluating the association between levels of thyroid hormones and TSH with body composition, and/or body fat distribution were carried out. It has been shown that BMI is positively associated with serum TSH levels (Knudsen et al. 2005, Nyrnes et al. 2006), and negatively related to fT4 levels, whereas it has been revealed that there is no association between BMI and fT3 (Knudsen et al. 2005).

The prevalence of apparent hypothyroidism (11.8\%) and subclinical hypothyroidism (7.7 \%) in morbidly obese subjects is high - $19.5 \%$ (Michalaki et al. 2006). Compared to normal weight subjects, morbidly obese have higher levels of total triiodothyronine, free triiodothyronine (fT3), total thyroxine, and thyrotropic hormone (TSH), probably due to the reset of their central thyrostat at higher level (Michalaki et al. 2006). Kozlowska and Rosolowska-Huszcz (2004) studied the effect of a 4-week weight regiment (20\% decreasing energy intake) on antropometric and hormonal parameters in obese woman. In response to the negative energy balance, the $\mathrm{T} 4$ to $\mathrm{TSH}$ ratio increased, whereas the fT4, T4, and fT4 to TSH ratio did not change. Therefore TSH serum concentration and its ratio to total thyroxine and free thyroxine (fT4) before weight reduction could be a good predictor of successful weight 
loss (Kozlowska and Rosolowska-Huszcz 2004). On the other hand, Manji et al. (2006) found no difference in serum TSH and free T4 between euthyroid lean and obese subjects. Another study revealed significant association of weight change with fT3, but not with fT4 in euthyroid adult subjects; weight gain over a 4-year period was associated with low serum T3 concentrations (Ortega et al. 2007). As suggested by Chomard et al. (1985), a decrease in serum total and fT3 concentrations is dependent on nutrient intake. It was obvious that thyroid dysfunction affects body weight; however, possible association of minor perturbations in thyroid function with changes in anthropometric measures needed be elucidated. Therefore, we attempted to evaluate the relationships between anthropometric characteristics and serum concentrations of the pituitary-thyroid axis hormones in a randomly selected sample of the Czech population.

\section{Methods}

\section{Subjects}

A sample of 1012 men and 1625 women (18-65 years of age), randomly selected from the Central registry of Czech Republic, was investigated in 15 areas. Levels of TSH, fT4 and fT3 in fasting serum samples were determined. Anthropometric characteristics including age, body weight, body height, body mass index (BMI), suprailiac skinfold (SIL), abdominal skinfold (ABD), subscapular skinfold (SSC), triceps skinfold (TRI), percent of body fat (Fat \%), lean body mass (LBM), waist circumference (Waist), hip circumference (Hip), neck circumference (Neck), waist to hip ratio (WHR), subscapular skinfold/triceps skinfold ratio (centrality index, CI) were measured according to the WHO recommendations (WHO Expert Committee 1995). BMI was calculated as the ratio of body weight $(\mathrm{kg})$ to body height $\left(\mathrm{m}^{2}\right)$. Centrality index was expressed as the subscapular skinfold to triceps skinfold ratio. Body composition was calculated from 4 skinfolds as reported elsewhere (Bláha et al. 2007, Pařízková 1977, Saller 1957).

\section{Analytical methods}

TSH was measured using commercially available noncompetitive immunoassay (normal range 0.17-4.2 mIU/l). The intra- and inter-assay coefficient of variation $(\mathrm{CV})$ of the method was $2.1 \%$ and $3.3 \%$. Both fT3 and fT4 were measured using competitive immunoassay. Normal range was $2.5-9.3 \mathrm{pmol} / \mathrm{l}$ (fT3) or 11.8 - $24.6 \mathrm{pmol} / 1$ (fT4), intra-assay coefficient of variation were $2.5 \%$ (fT3) and $2.9 \%$ (fT4), inter-assay coefficients of variation were $4.7 \%$ (fT3), and $6.6 \%$ (fT4).

\section{Statistical data analysis}

At first, the relationships between anthropometric characteristics and thyroid hormones were evaluated by age-adjusted Spearman's correlations. To check the homogeneity of the multivariate data set, the F-distributed Mahalanobis distance was computed. The experimental points for which the Mahalanobis distance reached significance $(p<0.001)$ were excluded from the correlation analysis as multivariate outliers.

Secondly, regression models were built which included one of the thyroid parameters as the dependent variable and four explanatory variables. As a general rule for constructing regression models the explanatory variables should be independent of each other to avoid problems with multicollinearity and to allow for simple interpretation of the results. Our main effort centered around the goal of finding a minimum number of explanatory variables describing all key features of the system under investigation. Thus the model consisted of the parameters of age, body composition, body fat distribution and body growth. In addition to age and height (as the parameters of body growth), the model included BMI as a body-composition indicator and $\mathrm{CI}$ as an indicator of body fat distribution. It is more common to express the indicator of body fat distribution by waist circumference. However, in contrast to CI, which exhibits low correlations with markers of body composition, waist circumference shared more than $50 \%$ of variability with the latter indices as was clearly demonstrated by the respective Spearman's correlation coefficients exceeding the value 0.7 (Table 3). It has been clearly demonstrated that skinfold indices measure a different dimension of fat distribution than circumference indices (Selby et al. 1990). There is also evidence of a genetic influence on subcutaneous fat distribution, but less evidence for such an influence on the WHR (Selby et al. 1990). WHR and centrality index do not measure the same dimension of fat patterning (Cardon et al. 1994).

Due to non-Gaussian data distribution in most of the variables, the original data was treated by a power transformation as described elsewhere (Meloun et al. 2000). The maximum conformity of the variables used in regression with Gaussian distribution was chosen in order 
to find the optimum transformation parameters. For this purpose, the two-parameter linear regression between fractiles of Gaussian distribution and fractiles of transformed variable was used. The optimum transformation parameter was reached at the maximum correlation coefficient of the linear regression and at the minimum of the mean standard error of prediction. The homogeneity of the data and further assumptions for correct regression analysis were checked using the regression diagnostics as described elsewhere (Meloun et al. 2004, Meloun et al. 2002).

Statgraphics Plus v. 5.1 from Manugistics (Rockville, MD, USA) and NCSS 2002 from Number Cruncher Statistical Systems (Kaysville, UT, USA) were used for data analysis.

\section{Results}

Table 1 shows the summary statistics of the anthropometric parameters and indices of thyroid function in the sample of randomly selected adults of both genders. The age-adjusted Spearman's correlations showed weak but significant relations between several anthropometric characteristics and thyroid parameters (Table 2). Due to the large complexity of the anthropometric parameters, multiple regression analysis (see data analysis) was more informative than correlation analysis. The regression model elucidated relationships between thyroid parameters and the four independent variables, which characterized the key features of age, body composition, fat distribution and growth, provided that the three remaining explanatory variables are constant. Table 3 shows age- and height-adjusted Spearman's correlations among anthropometric parameters, which were considered as independent indicators of body composition and body fat distribution in regression models. As shown on Table 3, Fat \%, waist circumference and BMI are strongly inter-correlated while the CI is relatively independent of the aforementioned parameters indicating the different character of this parameter.

As demonstrated in Table 4, fT3 in men is inversely correlated with age but positively with BMI. Alternatively, fT3 in women exhibits independence of all anthropometric parameters except for a negative correlation with CI (Table 5). fT4 negatively correlates with BMI in women only. TSH negatively correlates with age in men (Table 4) but not in women (Table 5). In both genders, positive correlation between TSH and CI was
Table 3. Age- and height-adjusted Spearman's correlations among Fat \%, waist circumference, body mass index and index of centralization (SSC/TRI ratio) in 1586 adult women and 985 adult men.

\section{Women \\ (upper right cells)}

$\begin{array}{cccc}\stackrel{0.751}{0} & \mathbf{0 . 7 5 0 1} & 0.057 \\ \text { 离 } & p=0.000 & p=0.000 & p=0.024\end{array}$

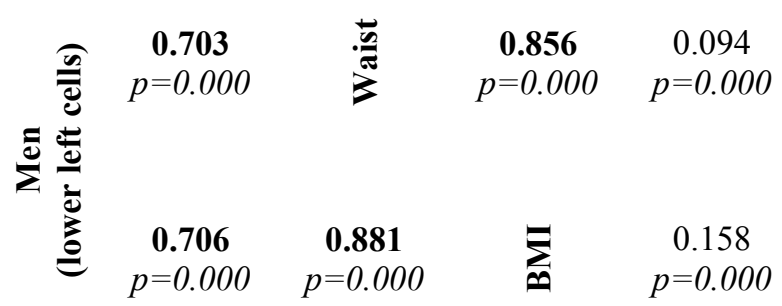

$\begin{array}{cccc}0.127 & \mathbf{0 . 2 0 8} & 0.197 & \overline{\widetilde{\sigma}} \\ p=0.000 & p=0.000 & p=0.000 & \underset{Ð}{\sigma}\end{array}$

SSC - subscapular skinfold, TRI - triceps skinfold, Fat \% - per cent of body fat, BMI - body mass index. The upper and lower parts of the cells represent correlation coefficients and their statistical significances. Relationships with correlation coefficients $>0.2$ are in bold.

observed. Positive correlation of BMI with TSH was shown in women only (Tables 4 and 5). The fT3/fT4 ratio, which may reflect deiodinase activity, negatively correlates with age but positively with BMI in both genders (Tables 4 and 5). In addition, women exhibit negative correlations of the fT3/fT4 ratio with CI (Table 5).

\section{Discussion}

The aim of our study was to evaluate relationships between pituitary-thyroid axis hormones and anthropometric characteristics in a representative sample of the population of Czech adults. Because of low correlations with the remaining explanatory variables, the selection of age, height, BMI (as parameter of body composition) and CI (as parameter of body fat distribution) appeared to be an optimum combination of independent variables for building a regression model (see Table 3). Except for the aforementioned correlations, the remaining explanatory variables used in the model are relatively independent of each other, which mean that 
Table 1. Anthropometric characteristics and thyroid parameters in a random, representative sample of the Czech population.

\begin{tabular}{|c|c|c|c|c|c|c|}
\hline \multirow[t]{2}{*}{ Variable } & \multicolumn{3}{|c|}{$\begin{array}{c}\text { Men } \\
(n=1012)\end{array}$} & \multicolumn{3}{|c|}{$\begin{array}{c}\text { Women } \\
(n=1625)\end{array}$} \\
\hline & mean & SD & median & mean & SD & median \\
\hline Age (years) & 41.8 & 13.7 & 44.0 & 42.2 & 12.4 & 44.0 \\
\hline Body weight (kg) & 82.2 & 13.8 & 81.6 & 69.6 & 14.2 & 67.2 \\
\hline Height $(\mathrm{cm})$ & 176 & 7 & 176 & 164 & 6 & 164 \\
\hline$B M I\left(\mathrm{~kg} / \mathrm{m}^{2}\right)$ & 26.5 & 4.3 & 26.2 & 26.2 & 5.0 & 25.6 \\
\hline Suprailiac skinfold (mm) & 13.7 & 7.9 & 12.0 & 16.4 & 8.2 & 15.0 \\
\hline Abdominal skinfold (mm) & 20.9 & 11.4 & 20.0 & 25.0 & 10.1 & 25.0 \\
\hline Subscapular skinfold (mm) & 17.6 & 8.3 & 16.0 & 22.3 & 11.3 & 20.0 \\
\hline Triceps skinfold (mm) & 17.7 & 7.7 & 18.0 & 21.5 & 8.8 & 20.0 \\
\hline Fat $(\%)$ & 16.3 & 4.7 & 15.9 & 18.1 & 5.3 & 18.3 \\
\hline Lean body mass (\%) & 83.7 & 5.4 & 84.1 & 81.9 & 6.9 & 81.7 \\
\hline Waist $(\mathrm{cm})$ & 98 & 12 & 98 & 96 & 15 & 94 \\
\hline$H i p(\mathrm{~cm})$ & 103 & 8 & 102 & 105 & 9 & 104 \\
\hline Neck circumference $(\mathrm{cm})$ & 42.1 & 6.0 & 41.0 & 36.4 & 2.9 & 36.0 \\
\hline WHR & 0.96 & 0.09 & 0.96 & 0.93 & 0.09 & 0.92 \\
\hline Subscapular skinfold/triceps skinfold & 1.015 & 0.306 & 1.000 & 1.048 & 0.396 & 1.000 \\
\hline Free triiodothyronine $(\mathrm{pmol} / \mathrm{l})$ & 5.9 & 1.5 & 5.8 & 5.4 & 1.7 & 5.2 \\
\hline Free thyroxine $(\mathrm{pmol} / \mathrm{l})$ & 16.2 & 2.8 & 16.1 & 15.6 & 2.9 & 15.3 \\
\hline$T S H(m I U / l)$ & 2.3 & 18.7 & 1.4 & 2.0 & 3.7 & 1.4 \\
\hline$f T 3 / f T 4$ & 0.373 & 0.108 & 0.357 & 0.355 & 0.113 & 0.335 \\
\hline
\end{tabular}

they are suitable for building the regression model.

In contradiction to the report of Manji et al. (2006) and coworkers, our data concerning a normal adult population showed a number of relatively weak but highly significant relationships between anthropometric characteristics and pituitary-thyroid gland function. Iodine supplementation in this sample was not examined. However, Knudsen et al. (2005) failed to find any significant association of iodine supplementation with BMI. It is apparent that currently BMI is much more influenced by total energy and nutrient intake and physical activity level and resulting energy balance than by iodine intake per se, but only under normal conditions.

Some of the relations between anthropometric indices and thyroid parameters were gender specific. In men all thyroid indices (fT3, fT4, TSH, and fT3/fT4 ratio) negatively correlated with age (Table 4). In women only the fT3/fT4 ratio exhibited a negative relationship with age (Table 5). In men, fT3 positively correlated with BMI but not with CI or body height (Table 4), although in women fT3negatively correlated with CI but not with other parameters (Table 5). In both genders, TSH positively correlated with CI. TSH was independent of
BMI in men but correlated positively with BMI in women (Tables 4 and 5). Knudsen et al. (2005) revealed positive correlation between TSH and BMI in both genders. This positive association is caused by signals from adipose tissue, which produces leptin (Anderlová et al. 2006), playing an important role in the central regulation of thyroid function via stimulation of TRH (Knudsen et al. 2005). Zimmerman-Belsing et al. (2003) found positive correlation between serum leptin and serum TSH. The increase in TSH levels may reflect a higher need for production of thyroid hormones with increasing BMI. Some authors demonstrated that the leptin-induced increase in TSH secretion via hypothalamic effects lead to an increase in serum free T4 (Chan et al. 2003, Welt et al. 2004). On the contrary, women examined in our study exhibited a decrease in serum fT4 with increasing BMI. This is in agreement with the findings of Knudsen et al. (2005), who demonstrated decreased fT4 with the increase of BMI in both genders. This situation gives support to the hypothesis that alterations in thyroid function with normal pituitary feedback regulation (high TSH and low fT4) is the primary event, while alterations BMI via 
Table 2. Age-adjusted Spearman's correlations between anthropometric characteristics and thyroid parameters in 986 adult men and 1586 adult women.

\begin{tabular}{|c|c|c|c|c|c|c|c|c|}
\hline & \multicolumn{4}{|c|}{ Men } & \multicolumn{4}{|c|}{ Women } \\
\hline & 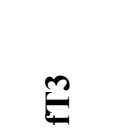 & $\vec{E}$ & $\underset{\mathscr{n}}{\mathbb{2}}$ & 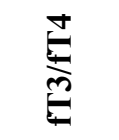 & 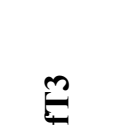 & $\dot{E}$ & $\underset{\mathscr{2}}{\bar{n}}$ & $\stackrel{+}{t}$ \\
\hline \multirow[t]{2}{*}{ Weight } & 0.030 & -0.023 & 0.046 & 0.044 & -0.008 & -0.073 & 0.072 & 0.027 \\
\hline & 0.340 & 0.469 & 0.146 & 0.163 & 0.761 & 0.004 & 0.004 & 0.280 \\
\hline \multirow[t]{2}{*}{ Height } & -0.038 & 0.000 & 0.049 & -0.044 & -0.069 & 0.014 & 0.009 & -0.073 \\
\hline & 0.239 & 0.997 & 0.124 & 0.165 & 0.006 & 0.586 & 0.719 & 0.004 \\
\hline \multirow[t]{2}{*}{$B M I$} & 0.067 & -0.016 & 0.011 & 0.073 & 0.021 & -0.088 & 0.072 & 0.061 \\
\hline & 0.037 & 0.614 & 0.725 & 0.022 & 0.399 & 0.000 & 0.004 & 0.015 \\
\hline \multirow[t]{2}{*}{$S I L$} & 0.022 & -0.058 & 0.094 & 0.061 & 0.032 & -0.146 & 0.050 & 0.103 \\
\hline & 0.497 & 0.068 & 0.003 & 0.055 & 0.200 & 0.000 & 0.047 & 0.000 \\
\hline \multirow[t]{2}{*}{$A B D$} & 0.012 & -0.069 & 0.054 & 0.048 & 0.048 & -0.124 & -0.009 & 0.104 \\
\hline & 0.712 & 0.031 & 0.091 & 0.129 & 0.055 & 0.000 & 0.726 & 0.000 \\
\hline \multirow[t]{2}{*}{$S S C$} & 0.020 & -0.071 & 0.048 & 0.060 & -0.045 & -0.080 & 0.063 & 0.002 \\
\hline & 0.536 & 0.026 & 0.136 & 0.060 & 0.071 & 0.001 & 0.012 & 0.928 \\
\hline \multirow[t]{2}{*}{$T R I$} & 0.049 & -0.094 & 0.037 & 0.097 & 0.045 & -0.104 & 0.013 & 0.095 \\
\hline & 0.122 & 0.003 & 0.241 & 0.002 & 0.070 & 0.000 & 0.618 & 0.000 \\
\hline \multirow[t]{2}{*}{ Fat $\%$} & 0.027 & -0.078 & 0.061 & 0.071 & 0.020 & -0.120 & 0.033 & 0.079 \\
\hline & 0.400 & 0.015 & 0.056 & 0.025 & 0.427 & 0.000 & 0.194 & 0.002 \\
\hline \multirow[t]{2}{*}{$L B M \%$} & -0.012 & 0.063 & -0.050 & -0.045 & -0.036 & 0.116 & 0.003 & -0.088 \\
\hline & 0.715 & 0.048 & 0.117 & 0.157 & 0.157 & 0.000 & 0.907 & 0.000 \\
\hline \multirow[t]{2}{*}{ Waist } & 0.069 & -0.033 & 0.047 & 0.086 & 0.109 & -0.075 & 0.041 & 0.134 \\
\hline & 0.030 & 0.305 & 0.144 & 0.007 & 0.000 & 0.003 & 0.104 & 0.000 \\
\hline \multirow[t]{2}{*}{ Hip } & 0.077 & -0.014 & 0.022 & 0.075 & 0.011 & -0.085 & 0.080 & 0.049 \\
\hline & 0.015 & 0.654 & 0.492 & 0.018 & 0.660 & 0.001 & 0.001 & 0.050 \\
\hline \multirow[t]{2}{*}{ Neck } & 0.100 & -0.003 & 0.011 & 0.093 & 0.053 & -0.009 & 0.065 & 0.054 \\
\hline & 0.002 & 0.918 & 0.732 & 0.003 & 0.033 & 0.715 & 0.009 & 0.033 \\
\hline \multirow[t]{2}{*}{ WHR } & 0.014 & -0.047 & 0.083 & 0.051 & 0.169 & -0.037 & -0.011 & 0.172 \\
\hline & 0.670 & 0.145 & 0.009 & 0.110 & 0.000 & 0.138 & 0.653 & 0.000 \\
\hline \multirow[t]{2}{*}{$C I$} & -0.063 & 0.076 & 0.014 & -0.095 & -0.137 & 0.089 & 0.055 & -0.169 \\
\hline & 0.050 & 0.018 & 0.651 & 0.003 & 0.000 & 0.000 & 0.027 & 0.000 \\
\hline
\end{tabular}

SIL - suprailiac skinfold, ABD - abdominal skinfold, SSC - subscapular skinfold, TRI - triceps skinfold, Fat \% - per cent of body fat, LBM lean body mass, Neck - neck circumference, WHR - waist to hip ratio, CI - (Centrality index, SSC/TRI), fT3 - free triiodothyronine, fT4 free thyroxine (Significant correlations are in bold. The upper and lower parts of the cells represent correlation coefficients and their statistical significances.)

alterations in energy expenditure the secondary event. The increase in BMI and fat mass may then lead to an increase in leptin, and a positive correlation between TSH and serum leptin would be expected. The fT3/fT4 ratio, probably reflecting deiodinase activity (Maia et al. 2005), negatively correlated with age but positively with BMI regardless of gender (Tables 4 and 5). The latter finding allows speculation about a compensatory mechanism counterbalancing either relative iodine deficiency or lower production of TSH via increase in deiodinase activity. In contrast to the positive correlation of fT3/fT4 ratio with BMI which was independent of gender, the negative correlation of the fT3/fT4 ratio with CI was specific to women only (Table 5). 
Table 4. Relationships between thyroid parameters and anthropometric characteristics in 1012 men as evaluated by multiple regression (for details see Statistical data analysis).

\begin{tabular}{|c|c|c|c|c|c|c|c|c|c|}
\hline \multirow[b]{2}{*}{ 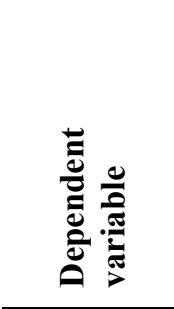 } & \multicolumn{4}{|c|}{$\begin{array}{l}\text { All variables } \\
\text { Parameter }\end{array}$} & \multirow[b]{2}{*}{ 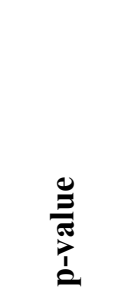 } & \multicolumn{3}{|c|}{$\begin{array}{l}\text { Backward stepwise regression } \\
\text { Parameter }\end{array}$} & \multirow[b]{2}{*}{ 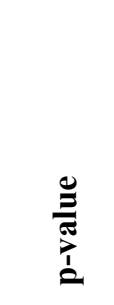 } \\
\hline & 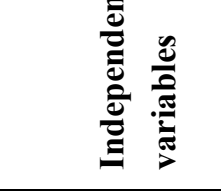 & 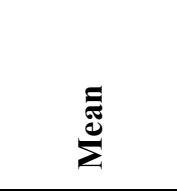 & 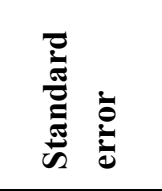 & 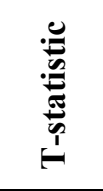 & & $\stackrel{\Xi}{\Sigma}$ & 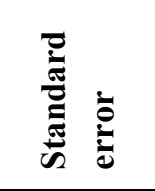 & 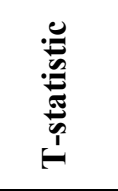 & \\
\hline \multirow{6}{*}{$f T 3^{0.5}$} & CONSTANT & 2.78 & 0.26 & 10.9 & 0.0000 & 2.93 & 0.16 & 18.6 & 0.0000 \\
\hline & Age & -0.00488 & 0.00082 & -5.94 & 0.0000 & -0.00468 & 0.00079 & -5.94 & 0.0000 \\
\hline & $-\left(B M I^{-0.5}\right)$ & 1.78 & 0.71 & 2.53 & 0.0115 & 1.65 & 0.71 & 2.33 & 0.0197 \\
\hline & $\log (S S C / T R I)$ & -0.0202 & 0.0347 & -0.58 & 0.5603 & ----- & ----- & ----- & ----- \\
\hline & $-\left(\right.$ Height $\left.^{-1.2}\right)$ & -0.0896 & 0.1026 & -0.87 & 0.3825 & ----- & ----- & ----- & ----- \\
\hline & & \multicolumn{4}{|c|}{$R^{2}=3.56 \%, p<0.0001$} & \multicolumn{4}{|c|}{$R^{2}=3.45 \%, p<0.0001$} \\
\hline \multirow{6}{*}{$f T 4^{0.22}$} & CONSTANT & 1.80 & 0.05 & 35.0 & 0.0000 & 1.87 & 0.01 & 304.9 & 0.0000 \\
\hline & Age & -0.000628 & 0.000166 & -3.78 & 0.0002 & -0.000753 & 0.000139 & -5.41 & 0.0000 \\
\hline & $-\left(B M I^{0.5}\right)$ & -0.297 & 0.143 & -2.09 & 0.0370 & ----- & ----- & ---- & ----- \\
\hline & $\log (S S C / T R I)$ & 0.00986 & 0.00698 & 1.41 & 0.1579 & ----- & ----- & ----- & ----- \\
\hline & $-\left(\right.$ Height $\left.^{-1.2}\right)$ & -0.00247 & 0.02070 & -0.12 & 0.9052 & ---- & ----- & ----- & ---- \\
\hline & & \multicolumn{4}{|c|}{$R^{2}=3.41 \%, p<0.0001$} & \multicolumn{4}{|c|}{$R^{2}=2.87 \%, p<0.0001$} \\
\hline \multirow{6}{*}{$T S H^{0.1}$} & CONSTANT & 1.11 & 0.05 & 22.5 & 0.0000 & 1.05 & 0.01 & 177.6 & 0.0000 \\
\hline & Age & -0.000314 & 0.000158 & -1.99 & 0.0466 & -0.000354 & 0.000134 & -2.64 & 0.0083 \\
\hline & $-\left(B M I^{0.5}\right)$ & 0.0624 & 0.1358 & 0.46 & 0.6457 & ----- & ----- & ----- & ----- \\
\hline & $\log (S S C / T R I)$ & 0.0146 & 0.0067 & 2.19 & 0.0282 & 0.0139 & 0.0067 & 2.07 & 0.0382 \\
\hline & $-\left(H e i g h t^{-1.2}\right)$ & 0.0245 & 0.0197 & 1.24 & 0.2143 & ----- & ----- & ----- & ----- \\
\hline & & \multicolumn{4}{|c|}{$R^{2}=1.29 \%, p=0.0127$} & \multicolumn{4}{|c|}{$R^{2}=1.03 \%, p=0.0064$} \\
\hline \multirow{6}{*}{$(f T 3 / f T 4)^{0.1}$} & CONSTANT & 0.938 & 0.021 & 43.7 & 0.0000 & 0.950 & 0.013 & 71.7 & 0.0000 \\
\hline & Age & -0.000246 & 0.000069 & -3.57 & 0.0004 & -0.000236 & 0.000066 & -3.57 & 0.0004 \\
\hline & $-\left(B M I^{0.5}\right)$ & 0.199 & 0.059 & 3.36 & 0.0008 & 0.192 & 0.060 & 3.23 & 0.0012 \\
\hline & $\log (S S C / T R I)$ & -0.00266 & 0.00292 & -0.91 & 0.3610 & ----- & ----- & ----- & ----- \\
\hline & $-\left(\right.$ Height $\left.t^{-1.2}\right)$ & -0.00701 & 0.00862 & -0.81 & 0.4160 & ----- & ----- & ----- & ----- \\
\hline & & \multicolumn{4}{|c|}{$R^{2}=1.69 \%, p=0.0019$} & \multicolumn{4}{|c|}{$R^{2}=1.54 \%, p=0.0004$} \\
\hline
\end{tabular}

SSC - subscapular skinfold, TRIC - triceps skinfold, fT3 - free triiodothyronine, fT4 - free thyroxine $\mathrm{R}^{2}$ - variability of dependent variable explained by the model

\section{Conclusions}

Our study demonstrated significant relationships between body composition, body fat distribution and parameters of the pituitary-thyroid axis. Some of these relations were gender-specific. We observed that the fT3/fT4 ratio was inversely related to age and positively related to BMI in both genders. The $\mathrm{fT} 3 / \mathrm{fT} 4$ ratio reflects deiodinase activity which might be largely influenced by energy and nutrient intake.

\section{Conflict of Interest}

There is no conflict of interest.

\section{Acknowledgements}

This study was supported by grant NB 7800-4 from the Internal Grant Agency of Ministry of Health of the Czech Republic. 
Table 5. Relationships between thyroid parameters and anthropometric characteristics in 1625 women as evaluated by multiple regression (for details see Statistical data analysis).

\begin{tabular}{|c|c|c|c|c|c|c|c|c|c|}
\hline 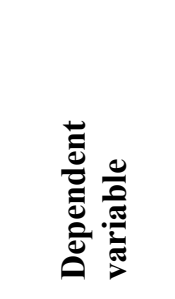 & 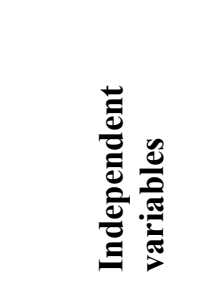 & $\begin{array}{l}\text { All variabl } \\
\text { Parameter }\end{array}$ & 胥 & 惑 & 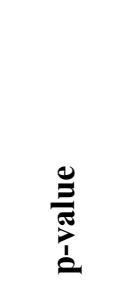 & $\begin{array}{l}\text { Backward s } \\
\text { Parameter }\end{array}$ & 总 & ession & 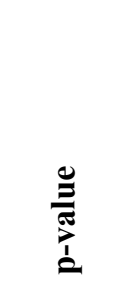 \\
\hline \multirow{6}{*}{$f T 3^{0.5}$} & CONSTANT & 2.20 & 0.20 & 10.9 & 0.0000 & 2.30 & 0.01 & 304.5 & 0.0000 \\
\hline & Age & -0.00164 & 0.00072 & -2.29 & 0.0220 & ----- & ----- & ----- & ----- \\
\hline & $-\left(B M I^{-0.5}\right)$ & 0.720 & 0.451 & 1.60 & 0.1104 & ----- & ----- & ----- & ----- \\
\hline & $\log (S S C / T R I)$ & -0.159 & 0.027 & -5.78 & 0.0000 & -0.161 & 0.028 & -5.72 & 0.0000 \\
\hline & $-\left(\right.$ Height $\left.^{-1.2}\right)$ & -0.142 & 0.078 & -1.82 & 0.0683 & ----- & ----- & ----- & ----- \\
\hline & & \multicolumn{4}{|c|}{$R^{2}=2.53 \%, p<0.0001$} & \multicolumn{4}{|c|}{$R^{2}=2.00 \%, p<0.0001$} \\
\hline \multirow{6}{*}{$f T 4^{0.22}$} & CONSTANT & 1.76 & 0.04 & 43.5 & 0.0000 & 1.78 & 0.02 & 113.1 & 0.0000 \\
\hline & Age & 0.000174 & 0.000144 & 1.21 & 0.2257 & ----- & ----- & ----- & ----- \\
\hline & $-\left(B M I^{-0.5}\right)$ & -0.300 & 0.091 & -3.31 & 0.0009 & -0.238 & 0.079 & -3.03 & 0.0024 \\
\hline & $\log (S S C / T R I)$ & 0.0101 & 0.0055 & 1.83 & 0.0675 & ----- & ----- & ----- & ----- \\
\hline & $-\left(\right.$ Height $\left.^{-1.2}\right)$ & 0.00302 & 0.01557 & 0.19 & 0.8463 & ----- & ----- & ----- & ----- \\
\hline & & \multicolumn{4}{|c|}{$R^{2}=0.832 \%, p=0.0102$} & \multicolumn{4}{|c|}{$R^{2}=0.578 \%, p=0.0024$} \\
\hline \multirow{6}{*}{$T S H^{0.1}$} & CONSTANT & 1.14 & 0.04 & 27.2 & 0.0000 & 1.08 & 0.02 & 65.5 & 0.0000 \\
\hline & Age & -0.000066 & 0.000148 & -0.45 & 0.6544 & ----- & ----- & ----- & ----- \\
\hline & $-\left(B M \Gamma^{0.5}\right)$ & 0.274 & 0.094 & 2.93 & 0.0034 & 0.229 & 0.083 & 2.78 & 0.0055 \\
\hline & $\log (S S C / T R I)$ & 0.0161 & 0.0057 & 2.82 & 0.0048 & 0.0162 & 0.0057 & 2.84 & 0.0046 \\
\hline & $-\left(\right.$ Height $\left.^{-1.2}\right)$ & 0.0192 & 0.0160 & 1.20 & 0.2313 & ----- & ----- & ----- & ----- \\
\hline & & \multicolumn{4}{|c|}{$R^{2}=1.36 \%, p=0.0003$} & \multicolumn{4}{|c|}{$R^{2}=0.769 \%, p=0.0006$} \\
\hline \multirow{6}{*}{$(f T 3 / f T 4)^{0.1}$} & CONSTANT & 0.904 & 0.017 & 53.6 & 0.0000 & 0.931 & 0.009 & 104.5 & 0.0000 \\
\hline & Age & -0.000172 & 0.000060 & -2.88 & 0.0039 & -0.000143 & 0.000058 & -2.48 & 0.0132 \\
\hline & $-(B M I-0.5)$ & 0.128 & 0.038 & 3.40 & 0.0007 & 0.137 & 0.038 & 3.64 & 0.0003 \\
\hline & $\log (S S C / T R I)$ & -0.0126 & 0.0023 & -5.51 & 0.0000 & -0.0130 & 0.0023 & -5.65 & 0.0000 \\
\hline & $-\left(\right.$ Height $\left.^{-1.2}\right)$ & -0.0123 & 0.0065 & -1.89 & 0.0588 & ----- & ----- & ----- & ---- \\
\hline & & \multicolumn{4}{|c|}{$R^{2}=2.74 \%, p<0.0001$} & \multicolumn{4}{|c|}{$R^{2}=2.57 \%, p<0.0001$} \\
\hline
\end{tabular}

SSC - subscapular skinfold, TRIC - triceps skinfold, fT3 - free triiodothyronine, fT4 - free thyroxine $\mathrm{R}^{2}$ - variability of dependent variable explained by the model

\section{References}

ANDERLOVÁ K, KŘEMEN J, DOLEŽALOVÁ R, HOUSOVÁ J, HALUZÍKOVÁ D, KUNEŠOVÁ M, HALUZÍK M: The influence of very-low-calorie-diet on serum leptin, soluble leptin receptor, adiponectin and resistin levels in obese women. Physiol Res 55: 277-283, 2006.

BLÁHA P, SUSANNE C, REBATO E: Essentials of Biological Anthropology. Charles University, Prague, 2007.

CARDON LR, CARMELLI D, FABSITZ RR, REED T: Genetic and environmental correlations between obesity and body fat distribution in adult male twins. Hum Biol 66: 465-479, 1994. 
CHAN JL, HEIST K, DEPAOLI AM, VELDHUIS JD, MANTZOROS CS: The role of falling leptin levels in the neuroendocrine and metabolic adaptation to short-term starvation in healthy men. J Clin Invest 111: 1409$1421,2003$.

CHOMARD P, VERNHES G, AUTISSIER N, DEBRY G: Serum concentrations of total T4, T3, reverse T3 and free T4, T3 in moderately obese patients. Hum Nutr Clin Nutr 39: 371-378, 1985.

KNUDSEN N, LAURBERG P, RASMUSSEN L B, BULOW I, PERRILD H, OVESEN L, JORGENSEN T: Small differences in thyroid function may be important for body mass index and the occurrence of obesity in the population. J Clin Endocrinol Metab 90: 4019-4024, 2005.

KOZLOWSKA L, ROSOLOWSKA-HUSZCZ D: Leptin, thyrotropin, and thyroid hormones in obese/overweight women before and after two levels of energy deficit. Endocrine 24: 147-153, 2004.

MAIA AL, KIM BW, HUANG SA, HARNEY JW, LARSEN PR: Type 2 iodothyronine deiodinase is the major source of plasma T3 in euthyroid humans. J Clin Invest 115: 2524-2533, 2005.

MANJI N, BOELAERT K, SHEPPARD MC, HOLDER RL, GOUGH SC, FRANKLYN JA: Lack of association between serum TSH or free T4 and body mass index in euthyroid subjects. Clin Endocrinol (Oxf) 64: 125-128, 2006.

MELOUN M, HILL M, MILITKÝ J, KUPKA K: Transformation in the PC-aided biochemical data analysis. Clin Chem Lab Med 38: 553-559, 2000.

MELOUN M, MILITKÝ J, HILL M, BRERETON RG: Crucial problems in regression modelling and their solutions. Analyst 127: 433-450, 2002.

MELOUN M, HILL M, MILITKÝ J, VRBÍKOVÁ J, STANICKÁ S, ŠKRHA J: New methodology of influential point detection in regression model building for the prediction of metabolic clearance rate of glucose. Clin Chem Lab Med 42: 311-322, 2004.

MICHALAKI MA, VAGENAKIS AG, LEONARDOU AS, ARGENTOU MN, HABEOS IG, MAKRI MG, PSYROGIANNIS AI, KALFARENTZOS FE, KYRIAZOPOULOU VE: Thyroid function in humans with morbid obesity. Thyroid 16: 73-78, 2006.

NYRNES A, JORDE R, SUNDSFJORD J: Serum TSH is positively associated with BMI. Int J Obes (Lond) 30: 100$105,2006$.

ORTEGA E, PANNACCIULLI N, BOGARDUS C, KRAKOFF J: Plasma concentrations of free triiodothyronine predict weight change in euthyroid persons. Am J Clin Nutr 85: 440-445, 2007.

PAŘÍZKOVÁ J: Body Fat and Physical Fitness. Martinus Nijhoff b.v., Publishers, Hague 1977.

SALLER M R K: Lehrbuch der Anthropologie in systematischer Darstellung. G. Fischer Verlag, Stuttgart, 1957.

SELBY JV, NEWMAN B, QUESENBERRY CP, JR., FABSITZ RR, CARMELLI D, MEANEY FJ, SLEMENDA C: Genetic and behavioral influences on body fat distribution. Int J Obes 14: 593-602, 1990.

WELT CK, CHAN JL, BULLEN J, MURPHY R, SMITH P, DEPAOLI AM, KARALIS A, MANTZOROS CS: Recombinant human leptin in women with hypothalamic amenorrhea. N Engl J Med 351: 987-997, 2004.

ZIMMERMANN-BELSING T, BRABANT G, HOLST JJ, ELDT-RASMUSSEN U: Circulating leptin and thyroid dysfunction. Eur J Endocrinol 149: 257-271, 2003. 